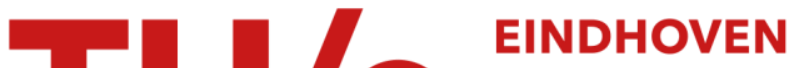 UNIVERSITY OF TECHNOLOGY
}

\section{A $44.5 \mathrm{GHz}$ differntially tuned VCO in $65 \mathrm{~nm}$ bulk CMOS with $8 \%$ tuning range}

\section{Citation for published version (APA):}

Cheema, H. M., Mahmoudi, R., Sanduleanu, M. A. T., \& Roermund, van, A. H. M. (2008). A $44.5 \mathrm{GHz}$ differntially tuned VCO in $65 \mathrm{~nm}$ bulk CMOS with $8 \%$ tuning range. In Proceedings of the EEE Radio Frequency Integrated Circuits Symposium, 2008 : RFIC 2008 ; June 15-17, 2008, Atlanta, Georgia, USA ; [held at] Microwave Week (pp. 649-652). Institute of Electrical and Electronics Engineers.

https://doi.org/10.1109/RFIC.2008.4561521

DOI:

10.1109/RFIC.2008.4561521

Document status and date:

Published: 01/01/2008

\section{Document Version:}

Publisher's PDF, also known as Version of Record (includes final page, issue and volume numbers)

\section{Please check the document version of this publication:}

- A submitted manuscript is the version of the article upon submission and before peer-review. There can be important differences between the submitted version and the official published version of record. People interested in the research are advised to contact the author for the final version of the publication, or visit the $\mathrm{DOI}$ to the publisher's website.

- The final author version and the galley proof are versions of the publication after peer review.

- The final published version features the final layout of the paper including the volume, issue and page numbers.

Link to publication

\section{General rights}

Copyright and moral rights for the publications made accessible in the public portal are retained by the authors and/or other copyright owners and it is a condition of accessing publications that users recognise and abide by the legal requirements associated with these rights.

- Users may download and print one copy of any publication from the public portal for the purpose of private study or research.

- You may not further distribute the material or use it for any profit-making activity or commercial gain

- You may freely distribute the URL identifying the publication in the public portal.

If the publication is distributed under the terms of Article $25 \mathrm{fa}$ of the Dutch Copyright Act, indicated by the "Taverne" license above, please follow below link for the End User Agreement:

www.tue.nl/taverne

Take down policy

If you believe that this document breaches copyright please contact us at:

openaccess@tue.nl

providing details and we will investigate your claim. 


\title{
A 44.5 GHz Differentially Tuned VCO in 65nm Bulk CMOS with $8 \%$ Tuning Range
}

\author{
Hammad M. Cheema ${ }^{1}$, Reza Mahmoudi ${ }^{1}$, M.A.T. Sanduleanu ${ }^{2}$, Arthur van Roermund ${ }^{1}$ \\ ${ }^{1}$ Department of Electrical Engineering, Mixed-signal Microelectronics group, Eindhoven University of \\ Technology, 5600 MB, Eindhoven, The Netherlands \\ ${ }^{2}$ Philips Research, Prof. Holstlaan 4, 5656A, Eindhoven, The Netherlands
}

\begin{abstract}
This paper presents a low power, low phase noise mm-wave voltage controlled oscillator. The VCO can be tuned from 41 to $44.5 \mathrm{GHz}(8 \%$ tuning range) and utilizes a differential tuning mechanism based on varactors and fixed MIM capacitors. Fabricated in a bulk CMOS $65 \mathrm{~nm}$ technology, it consumes $3.6 \mathrm{~mW}$ and exhibits a phase noise of $-106 \mathrm{dBc} / \mathrm{Hz}$ at $1 \mathrm{MHz}$ offset from a 41.2 GHz carrier. The resulting $\mathrm{FOM}$ is $-192.7 \mathrm{dBc} / \mathrm{Hz}$, which is the best reported value for VCOs operating above $40 \mathrm{GHz}$.

Index Terms - CMOS integrated circuits, Millimeter wave oscillators, Phase locked loops, Phase noise, Voltage controlled oscillators.
\end{abstract}

\section{INTRODUCTION}

Voltage-controlled oscillators (VCOs) are essential building blocks of wireless transceivers. Low power consumption, high output power, low phase noise, wide tuning range and reliability are key requirements of VCOs. These requirements become even more challenging as new applications emerge at mm-wave frequencies. Broadband WPAN at $60 \mathrm{GHz}$ ISM band, automotive radar sensors at $76 \mathrm{GHz}$ and imaging applications at $94 \mathrm{GHz}$ are some examples of mm-wave applications.

The design of mm-wave VCOs poses numerous challenges. At these frequencies, varactors, which are invariably used for tuning LC-VCOs, become the limiting factor for the overall tank quality factor. Furthermore, the value of the required passives is of the same order as parasitic capacitances and inductances. Therefore, accurate models of passives are vital for achieving correct oscillation frequency. In addition, layout dependent parasitics, which could deviate the VCO from its intended frequency range, also become a critical problem.

Many integrated CMOS VCOs operating above $40 \mathrm{GHz}$ have been reported in recent years [1]-[5]. In order to boost the oscillation frequency and improve quality factor of passives, high-resistivity substrates and SOI CMOS is being used [1]-[2]. However, these technologies require extra processing steps, thereby increasing the cost.
Similarly, special layout techniques for transistors and passive devices, to minimize parasitics, have been demonstrated [4]. In this paper, a $44.5 \mathrm{GHz}$ complementary cross-coupled LC VCO is presented. MIM capacitors are used to improve the quality factor of the capacitive part of the tank. Differential tuning is adopted to improve phase noise performance. Chip layout has been carried out carefully to avoid unnecessary parasitics. The VCO has been implemented in a $65 \mathrm{~nm}$ bulk CMOS LP (low power) technology. In combination with a divider, the proposed VCO can be used, firstly, for a $60-\mathrm{GHz}$ double-conversion zero-IF (sliding-IF) receiver and secondly, for a $60-\mathrm{GHz}$ transmitter using a harmonic frequency tripler.

\section{VCO ARCHITECTURE}

The schematic of the VCO is shown in Fig. 1 (a). A complementary cross-coupled architecture is chosen for this design. As compared to NMOS-only VCO, the complementary structure provides higher transconductance at a given current, which results in faster switching and larger output amplitude. In addition, it demonstrates superior rise- and fall-time symmetry resulting in less upconversion of $1 / \mathrm{f}$ noise [6].

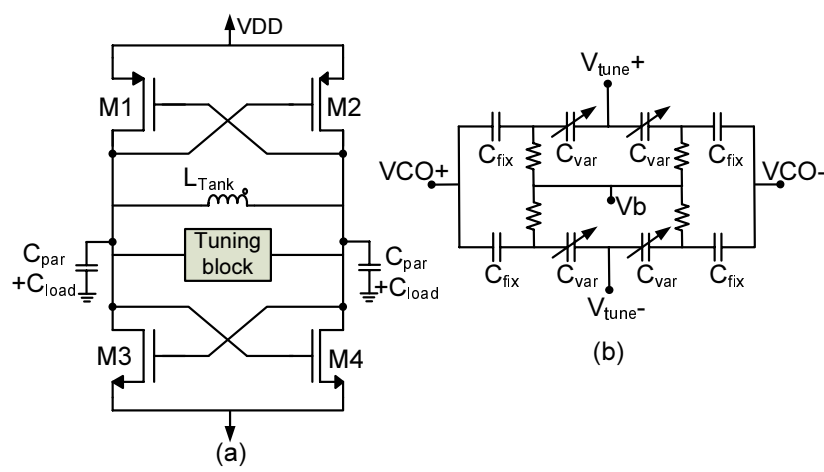

Fig. 1. (a) Complementary cross-coupled VCO, (b) Tuning 
The transistors M1 to M4 form the active part of the VCO. A ratio of two is chosen between negative transconductance and losses of the tank, to ensure reliable startup. In order to match the transconductance of PMOS and NMOS transistors, the former has twice the width. The resonator is composed of a single turn octagonal shaped inductor and a combination of varactors and fixed MIM capacitors. The VCO is tuned differentially. This minimizes common-mode noise from voltage supplies and other sources and improves the phase noise performance. An output buffer is included for measurement purposes. The differential outputs use 50 transmission lines to the bond-pads.

\section{RESONATOR AND OUTPUT BUFFER DESIGN}

At mm-wave frequencies the required inductors are small and exhibit a reasonably high quality factor (Q). In contrast, quality factor of the capacitive part, i.e. the varactors becomes the dominant factor. The quality factor of a $\mathrm{LC}$ tank $\left(\mathrm{Q}_{\mathrm{Tank}}\right)$ is given by,

$$
\frac{1}{Q_{\text {Tank }}}=\frac{1}{Q_{L}}+\frac{1}{Q_{C}}
$$

where $\mathrm{Q}_{\mathrm{L}}$ and $\mathrm{Q}_{\mathrm{C}}$ are quality factors of the inductor and capacitors that make up the tank. In case, $Q_{L}$ is much lower than $Q_{C}$, which is generally the case for frequencies up to a few gigahertz, improving $\mathrm{Q}_{\mathrm{L}}$ leads to a higher $\mathrm{Q}_{\text {Tank }}$. However, at mm-wave frequencies and with introduction of modern CMOS processes, the quality factor of the capacitor $\left(Q_{C}\right)$ is significantly lower than $Q_{L}[3]$. Thus, more design effort should be invested in improving $Q_{C}$ at mm-wave frequencies rather than improving $Q_{L}$.

\section{A. Inductor design}

The on-chip integrated inductor is a single turn octagonal shaped coil. It utilizes the thick top metal, to reduce series resistance, thereby increasing the quality factor. The inductor metal width and inner radius are $6 \mu \mathrm{m}$ and $15 \mu \mathrm{m}$, respectively. The simulated inductance value is $95 \mathrm{pH}$, with a quality factor of 20 at $40 \mathrm{GHz}$. The area occupied by the inductor is $60 \times 60 \mu \mathrm{m}$.

\section{B. Varactor design}

The tuning of VCO is achieved by combination of accumulation MOS (AMOS) varactors and fixed MIM capacitors (see Fig. 1 (b)).

Metal-insulated-metal (MIM) capacitors exhibit high Qfactors (above 20) at mm-wave frequencies due to low intrinsic losses. Thus, using them in series with varactors improves the quality factor, at the expense of reduced tuning range. The simulated tank capacitance and quality factor are shown in Fig. 2. The $\mathrm{C}_{\max } / \mathrm{C}_{\min }$ ratio of this setup is 2.1 and $\mathrm{Q}_{\mathrm{C}}$ varies between 8.5 and 14.3. The reduced capacitance ratio due to MIM capacitors is not an issue, as the desired frequency tuning range is still successfully achieved. The advantage on the other hand is that $\mathrm{Q}_{C}$ improves by approx. $40 \%$ as compared to a stand-alone varactor implementation.
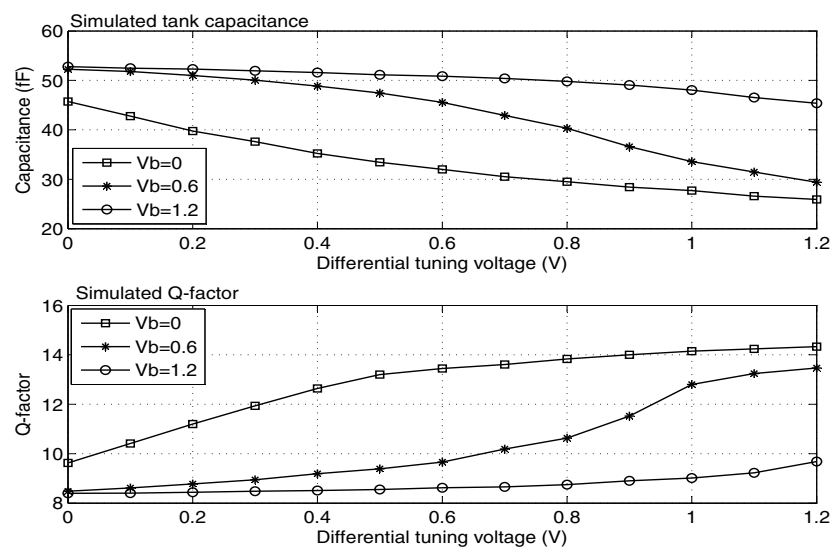

Fig. 2. Simulated tank capacitance and quality factor

In addition, some flexibility is achieved by connecting the lower terminal of the biasing resistors ( Vb in Fig. 1(b)) to an external supply instead of grounding them. This provides an extra control voltage to cater parasitics and process variation. Fig 2. shows the capacitance and $\mathrm{Q}_{\mathrm{C}}$ variation as a function of differential tuning voltage $\left(\mathrm{V}_{\text {tune+ }}\right.$ $-\mathrm{V}_{\text {tune. }}$ ) for three biasing voltages.

Differential tuning is adopted for the capacitive part of the LC-tank [2]. Common-mode noise can modulate the varactors, if the VCO is tuned from a single node. This noise appears as jitter and phase noise at the VCO output. Differential tuning alleviates this problem by reducing the common-mode noise, thus improving phase noise.

\section{Output buffer}

A common-source differential stage is designed as an output buffer, to make on-wafer measurements possible. In order to avoid loading of the VCO, the buffer is biased independently. This also helps in measuring the power consumption of VCO and buffer separately. The load resistance (silicided poly-silicon based) is 50 , to match it with the transmission lines as well as the measurement equipment. 


\section{LAYOUT AND TECHNOLOGY}

As mentioned earlier, layout is done carefully and compactly to reduce parasitics. The RF signal paths between the inductor, capacitive tuning part and transistors are kept as short as possible. Narrow connecting lines are avoided to minimize resistive losses. Ground meshing is used underneath the RF paths. Decoupling capacitors are included for the voltage supplies. The differential outputs use 50 transmission lines (TL's) to the bond-pads. These TL's are coplanar waveguide based with lateral ground-plane consisting of all metal layers. The width of the TL is $5 \mu \mathrm{m}$ and spacing from the ground plane is $4.22 \mu \mathrm{m}$.

The VCO is fabricated in TSMC bulk CMOS 65nm LP (low-power) process having six metallization layers. The process offers MIM capacitors and poly-silicon resistors. The measured $\mathrm{f}_{\mathrm{T}}$ of NMOS and PMOS transistors is 140 $\mathrm{GHz}$ and $80 \mathrm{GHz}$, respectively. Due to bond-pad limitation the total chip area is $700 \times 400 \mu \mathrm{m}$. However, the VCO core only occupies $100 \times 100 \mu \mathrm{m}$. The chip micrograph is shown in Fig. 3.

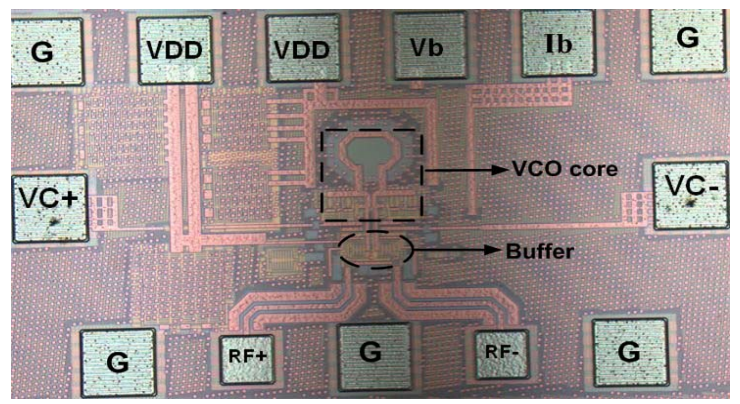

Fig. 3. Chip micrograph

\section{MEASUREMENT Results}

The VCO was measured on-wafer using a high frequency differential probe (GSGSG) and a $180^{\circ}$ hybrid coupler. An Agilent PSA series spectrum analyzer with phase noise functionality was used for spectral measurements. The measurement equipment generates considerable external noise, which can potentially degrade the measured results. In order to suppress the noise coming from power supplies, dedicated filters are employed. In addition, common-grounds between the supplies and spectrum analyzer are eliminated. The lighting of the viewing optics is turned-off during measurement [2]. It is noticed that central alignment of the infinity probes (on the bond-pads) and good probe contact yield stable and repeatable measurements.
The frequency tuning range (FTR) of the $\mathrm{VCO}$ is shown in Fig. 4, where output oscillation frequency is plotted versus differential tuning voltage for three bias voltages $(\mathrm{Vb})$. It can be seen that tuning curves follow the tank capacitance curves of Fig. 2. The minimum and maximum measured frequencies are $41 \mathrm{GHz}$ and $44.5 \mathrm{GHz}$ (see Fig. 5), respectively, giving a tuning range of $8.1 \%$.

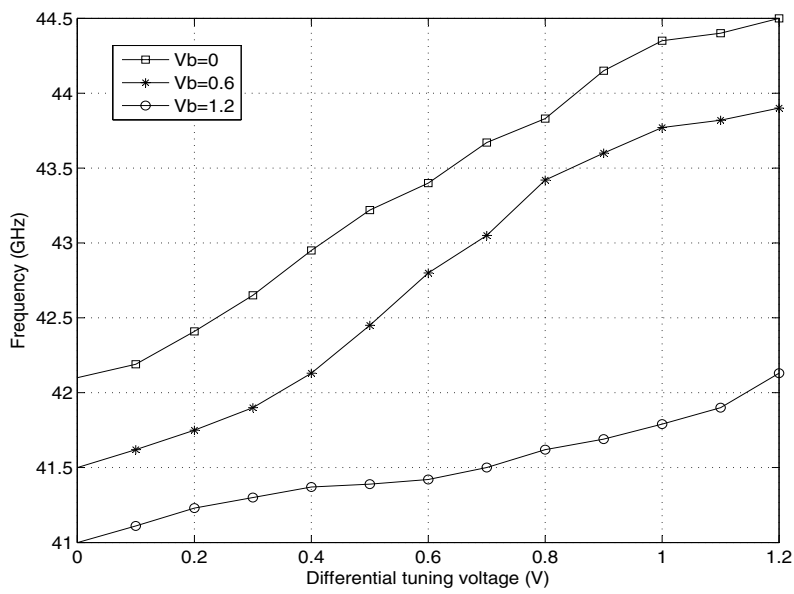

Fig. 4. VCO frequency tuning range

The VCO and output buffer consume $3 \mathrm{~mA}$ and $5 \mathrm{~mA}$ from a $1.2 \mathrm{~V}$ supply, respectively. The total loss from the wiring cables, connectors and hybrid was measured between 6 and $8 \mathrm{~dB}$ over the entire frequency tuning range. After deembedding this loss, the average differential output power delivered to a 50 load is between -2 and $-6 \mathrm{dBm}$ as shown in Fig. 6.

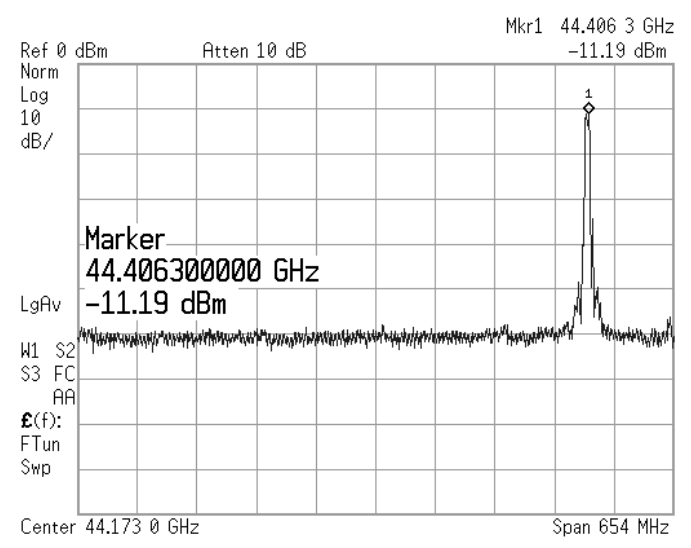

Fig. 5. VCO output spectrum at $44.4 \mathrm{GHz}$ 
TABLE I

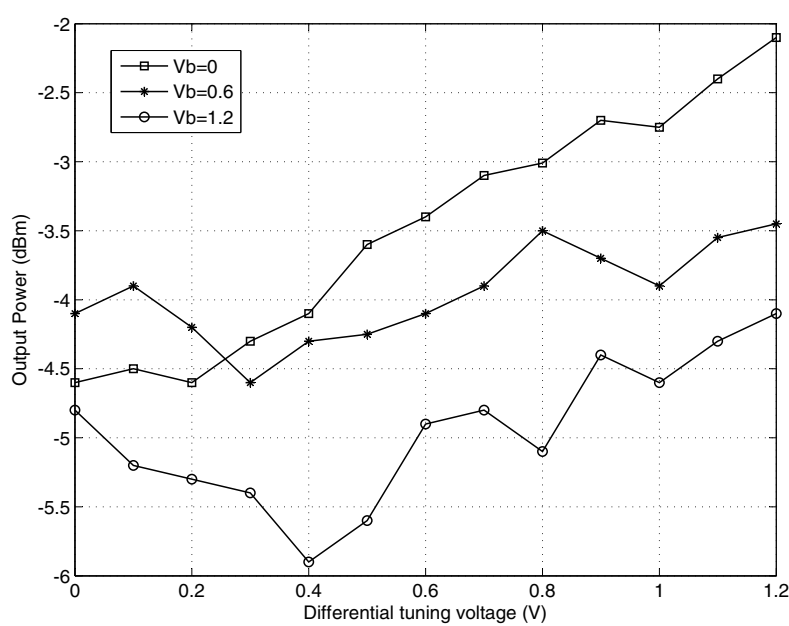

Fig. 6. VCO output power versus tuning voltage

The measured phase noise of the $\mathrm{VCO}$ at $41.2 \mathrm{GHz}$ is shown in Fig. 7. At $100 \mathrm{kHz}$ and $1 \mathrm{MHz}$ offsets, the measured values are -98 and $-106 \mathrm{dBc} / \mathrm{Hz}$, respectively. The commonly used FOM for VCOs is defined as $\mathrm{FOM}=\mathrm{L}\{\mathrm{f}\}-20 \log \left(\mathrm{f}_{\mathrm{o}} / \mathrm{f}\right)+10 \log \left(\mathrm{P}_{\mathrm{dc}} / 1 \mathrm{~mW}\right)$, where $L\{f\}$ is the measured phase noise at frequency offset $f$ from the carrier at $\mathrm{f}_{\mathrm{o}}$, and $\mathrm{P}_{\mathrm{dc}}$ is the $\mathrm{DC}$ power consumption [1]. Using the above expression and measured phase noise at $1-\mathrm{MHz}$ offset, a FOM of $-192.7 \mathrm{dBc} / \mathrm{Hz}$ is achieved, which is the best reported FOM for VCOs operating above 40 GHz. Table I compares, published state-of-the-art VCO's operating at mm-wave frequencies. The presented VCO has the lowest power-consumption (excluding output buffers) while achieving a reasonable frequency tuning range. The phase noise is better than reported SOI implementations in [1], [2].

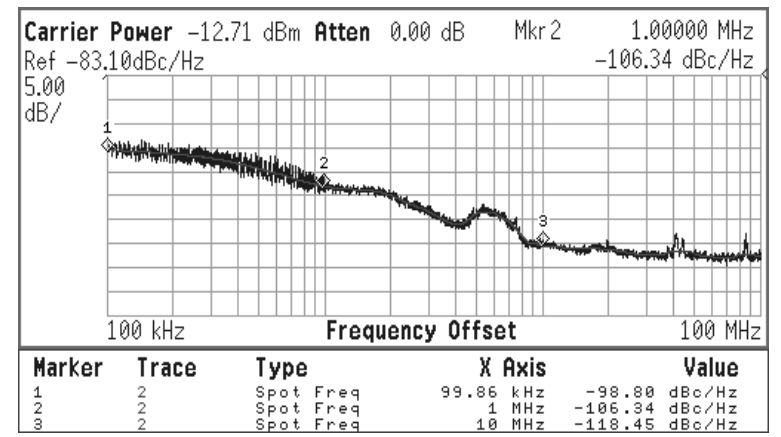

Fig. 7. VCO phase noise for a $41.2 \mathrm{GHz}$ carrier
COMPARISON WITH PUBLISHED RESUlTS

\begin{tabular}{|c|c|c|c|c|c|}
\hline $\begin{array}{l}\text { Ref. \& } \\
\text { Tech. }\end{array}$ & \begin{tabular}{|l} 
Freq. \\
(GHz)
\end{tabular} & \begin{tabular}{|l}
$P_{\mathrm{dc}}$ \\
$(\mathrm{mW})$
\end{tabular} & $\begin{array}{l}\text { FTR } \\
(\%)\end{array}$ & $\begin{array}{l}\mathrm{PN} @ \\
1 \mathrm{MHz} \\
(\mathrm{dBc} / \mathrm{Hz})\end{array}$ & \begin{tabular}{|l} 
FOM \\
$(\mathrm{dBc} / \mathrm{Hz})$
\end{tabular} \\
\hline $\begin{array}{l}\text { [1] } 0.13 \mu \mathrm{m} \\
\text { SOI CMOS }\end{array}$ & 40.7 & 11.3 & 15 & -89 & -170.6 \\
\hline $\begin{array}{l}{[2] 0.12 \mu \mathrm{m}} \\
\text { CMOS SOI }\end{array}$ & 44 & 7.5 & 9.8 & -101 & -185 \\
\hline $\begin{array}{l}{[3] 0.13 \mu \mathrm{m}} \\
\text { CMOS }\end{array}$ & 43 & 7 & 4.2 & -90 & -174.2 \\
\hline $\begin{array}{l}{[4] 0.13 \mu \mathrm{m}} \\
\text { CMOS }\end{array}$ & 59 & 9.8 & 10.2 & -89 & -174.5 \\
\hline $\begin{array}{l}\text { [5] } 0.18 \mu \mathrm{m} \\
\text { CMOS }\end{array}$ & 50 & 4 & 2 & -96 & -184 \\
\hline $\begin{array}{l}\text { This work } \\
65 \mathrm{~nm} \text { CMOS }\end{array}$ & 44.5 & 3.6 & 8.1 & -106 & -192.7 \\
\hline
\end{tabular}

\section{CONCLUSION}

We have presented a $44.5 \mathrm{GHz}$ complementary LC cross-coupled VCO implemented in a $65 \mathrm{~nm}$ bulk CMOS LP technology. The use of MIM capacitors to improve $\mathrm{Q}_{\mathrm{C}}$, differential tuning to reduce phase noise and compact layout to minimize parasitics yields good measured results. The VCO has a FTR of $8 \%$ and dissipates $3.6 \mathrm{~mW}$. The measured phase noise at $1 \mathrm{MHz}$ offset from a 41.2 $\mathrm{GHz}$ carrier is $-106 \mathrm{dBc} / \mathrm{Hz}$ resulting in an excellent $\mathrm{FOM}$ of $-192.7 \mathrm{dBc} / \mathrm{Hz}$.

\section{REFERENCES}

[1] Neric Fong et al., "A Low-Voltage 40-GHz Complementary VCO With $15 \%$ Frequency Tuning Range in SOI CMOS Technology," IEEE JSSC, vol. 39, pp. 841-846, May 2004.

[2] Jonghae Kim, J.-O Plouchart et al., "A $44 \mathrm{GHz}$ Differentially Tuned VCO with $4 \mathrm{GHz}$ Tuning Range in $0.12 \mu \mathrm{m}$ SOI CMOS," IEEE ISSCC, pp 416-417 and 607, Feb., 2005.

[3] Arnoud P. van der Wel et al., "A Robust 43-GHz VCO in CMOS for OC-768 SONET Applications," IEEE JSSC, vol. 39, pp. 1159-1163, July 2004.

[4] Changhua Cao, Kenneth K.O, "Millimeter-Wave VoltageControlled Oscillators in $0.13-\mu \mathrm{m}$ CMOS Technology," IEEE JSSC, vol. 41, pp. 1297-1304, June 2006.

[5] Tang-Nian Luo et al., "A 1-V CMOS VCO For $60-\mathrm{GHz}$ Applications," Asia Pacific Microwave Conf, Dec. 2005.

[6] Lin Jia et al., "9.3-10.4-GHz-Band Cross-Coupled Complementary Oscillator With Low Phase-Noise Performance,"IEEE Trans. On Microwave theory and Techniques, vol.52, pp.1273-1278, April 2004. 